\title{
"EL PEQUEÑO PUEBLO QUE SU NOMBRE CONSTA SÓLO DE UNA LETRA": LA EXTENSIÓN DEL QUESUISMO EN EL ESPAÑOL ACTUAL
}

\author{
"EL PEQUEÑO PUEBLO QUE SU NOMBRE \\ CONSTA SÓLO DE UNA LETRA": \\ THE SPREAD OF "QUESUISMO" \\ IN CURRENT SPANISH
}

\author{
Ana Serradilla Castaño \\ Universidad Autónoma de Madrid \\ ana.serradilla@uam.es
}

\begin{abstract}
RESUMEN: Este trabajo profundiza en el estudio del quesuismo en español actual -tanto americano como europeo- mediante el análisis de corpus como CREA, CORPES XXI, COSER y ESLORA. Asimismo, se muestran los resultados de una encuesta que permite observar cómo determinados parámetros sociolingüísticos pueden influir en su uso. Luego, se analizan los tipos de texto en los que aparece, las características de los hablantes que lo emplean, las funciones desempeñadas por que su y la naturaleza de los antecedentes a los que acompaña. Por último, se alude a los distintos factores que favorecen su aparición y consolidación.
\end{abstract}

Palabras clave: quesuismo; cuyo; inmediatez comunicativa; español actual; sociolingüística.

Abstract: This work intends to go in depth into the study of "quesuism" in current Spanish -both in its European and American variety- through the analysis of corpus such as CREA, CORPES XXI, COSER and ESLORA. Likewise, it shows the results of a survey that allows us to observe how certain sociolinguistic parameters can influence their use. In addition, we analyze the types of text in which it appears, the characteristics of the speakers who use it, the functions performed by que su and the nature of its antecedents. Finally, this paper refers to the different factors contributing to its appearance and consolidation.

Keywords: quesuismo; cuyo; communicative immediacy; current

Spanish; sociolinguistics.

Recepción: 22 de julio de 2018; aceptación: 27 de marzo de 2019.

D.R. () 2020. Nueva Revista de Filología Hispánica Licencia Creative Commons Attribution-NonCommercial (CC BY-NC) 4.0 International 
INTRODUCCIÓN*

Con este estudio, pretendo ofrecer un panorama de la extensión del quesuismo en el español contemporáneo. Construcciones como "el pequeño pueblo que su nombre consta sólo de una letra" o "el chico que su padre trabaja en el banco" se oyen, e incluso se leen, con relativa frecuencia en la actualidad. Esto se debe a que la expresión que + su es una fórmula habitual ya en español como alternativa a cuyo. Una y otra forma han convivido a lo largo de la historia y, hoy en día, en determinadas situaciones que + su parece estar a punto de desbancar a cuyo, sobre todo en textos orales, actos de habla coloquiales o textos escritos en los que prima la inmediatez comunicativa ${ }^{1}$. Respecto a esta última forma, Elvira señala:

Es un pronombre extraño o ausente en la gramática de muchos hablantes, con una frecuencia de uso mucho mayor en la lengua escrita que en la oral, lo que resulta ser una paradójica inversión del contexto latino de oralidad en el que surgió (2007, p. 365) ${ }^{2}$.

Efectivamente, cuyo es ahora visto, frente a la situación previa que comentaba Elvira, como una forma culta, y los hablantes tienden a sustituirla por la construcción que su, tal y como se recoge en toda la bibliografía al respecto. Esta sustitución no es, sin embargo, un fenómeno reciente, como he adelantado, sino que hunde sus raíces en la lengua de épocas anteriores. Así, dos autores como Elvira (2007) y Sánchez Lancis (2014) dan buena cuenta de su presencia en textos medievales. El primero de ellos nos muestra ejemplos como los siguientes:

Myo fijo guardate del omne que la su lengua es aboldonada \& suelta a dezir sienpre mentira (Castigos y Documentos para bien vivir, sig. XIII, DAVIES);

* Este trabajo ha sido realizado en el marco del proyecto de investigación PGC2018-095077-B-C42, dirigido por Inés Fernández-Ordóñez y Ana Serradilla Castaño.

${ }^{1}$ Sobre la cada vez menor utilización de cuyo en el español actual, son varios los autores que vienen reflexionando desde hace ya muchos años. Véanse, en esta línea, trabajos como los de Álvarez Martínez (1987-88) o LORENZO (1980).

${ }^{2}$ Elvira señala cómo en algunas otras lenguas románicas tuvo un carácter más vulgar, al igual que en latín. 
Avn ay otra fiebre que la su materia es muy sotil \& muy seca \& muy caliente (Israelí, Tratado de las fiebres, sig. XIV, DAVIES);

E la formjca que la su materia es muy delgada aquella es de ljgera materia apagada (Cirugía rimada, sig. xv, DAVIES).

También Sánchez Lancis (2014, p. 391), aparte de mostrar una importante documentación medieval, nos recuerda su existencia en el español clásico y hace una puntualización relevante, pues llama la atención sobre el hecho de que los ejemplos de quesuismo localizados pertenecen a autores cultos, lo que es buena muestra de que en la época podría ser una variante invisible, en terminología de Barra Jover (2009 y 2011) ${ }^{3}$, y de que, en ningún caso, se identificaría con un rasgo vulgar:

1. Hay sujetos que sus muchas prendas los hacen ser buscados de todos (1646, Baltasar Gracián, El discreto, cap. XI, España, CORDE).

2. á una mujer brava que su marido era cazador (1550-1606, Baltasar del Alcázar, Poesías, España, CORDE).

3. Hay otra casa de una viuda, que su marido se dixo apellido de Balboa, goza en posesion por executoria de Valladolid litigada por su abuelo con el concejo de Valdaracete y auto en que la mandaron dar sobrecarta en la Chancilleria de Granada (1575-1580, Anónimo, Relaciones histórico-geográficas-estadísticas de los pueblos. Reino de Toledo, España, CORDE) ${ }^{4}$.

Asimismo, Kany (1951, p. 133, apud DeMello 1992), al referirse a los escritores del Siglo de Oro, señala: "In the older language que su was commonly used for cuyo "whose", sin mencionar el posible carácter menos culto de la construcción.

${ }^{3}$ Según Barra Jover (2009, p. 21), "Una variante invisible existe cuando un mismo locutor puede usar para la función A la variante al y la variante a2 sin tener consciencia de ello (sin dominar la alternancia) y sin que ello dependa de la situación. Quisiera insistir en que lo que interesa es que se trate del mismo locutor y que sólo tiene interés observar la variante desde un punto de vista idiolectal y teniendo también en cuenta que el receptor tampoco es sensible a tales variantes". En los textos presentados a continuación, se hace evidente que el uso de que su por cuyo no se percibe como una forma estigmatizada.

${ }^{4}$ Pueden verse más ejemplos en Tsutsumi Hernández 2002. 
En el CORDIAM también es posible localizar ejemplos de quesuismo como los siguientes, que aparecen en diferentes tipos de documentos de siglos pasados ${ }^{5}$ :

4. En este nabío, y el portador desta es la señora Marina Ortiz de Goíbar, biuda, muger de Juan Ortiz de Ydígoras, natural de la villa de Hoñate, y en su conpañía della ba vn hidalgo de Burgos, que su padre fue de la dicha villa de Hoñate, y ella ba a su tierra y he procurado de mi parte en abiarle (1571, hombre, Audiencia de Lima, Virreinato del Perú, Documentos entre particulares: cartas y otros, CORDIAM).

5. ansi mismo ay Veinte y tantas esclauas hembras que su trabajo es de la misma manera de muy poco fruto por que se ocupan en limpiar los negros en que guisarles de comer y en otras menudencias de poca consideraçion (1609, hombre, La Habana, Capitanía General de Cuba, Documentos administrativos, CORDIAM).

6. Al señor don Marttín Orttiz de Lanzagortta me a de azer vuestra merced el fauor de mandármele encomendar mucho y que no le escriuo porque mis azidenttes no me dan lugar; y lo mismo a don $\{\mathrm{f} .2 \mathrm{v}\}$ Domingo de Villanueba y Susquiza y a estte que su ssobrino y haijado, don Francisco de Urttussáusttegui, lo rreziuió en su cassa y lo rremittió luego, aunque io les ofrezí biniesen a la mía, respondieron que ia esttauan allí; y al señor don Marttín que su aijado, aunque en cortta conuenienzia, esttá acomodado (1726, español, hombre, Ciudad de México, Audiencia de México, Virreinato de la Nueva España, Documentos entre particulares: cartas y otros, COR$D I A M)$.

7. Muy yllustre señor. \\ Don Francisco Antonio / Cao de esta vecindad a usía hace presente / que pasando con don Juan de Figueroa / después de la oración de la noche del día

${ }^{5}$ No debemos olvidar que la secuencia que su es muy frecuente en español en otras estructuras causales o completivas, lo que puede favorecer -por presión o contagio- la aparición de construcciones quesuistas. Así, en este corpus, efectivamente, es habitual la construcción que su en estructuras que no hay que catalogar dentro del quesuismo: "no mas sino que quedo rogando a mi dios que me / os traya a mis ojos y confiado en que no abra falta / en su venida etcétera de mexico y de marzo a 26 / de 1576 años / su ermana que su benida desea francisca p[ér] ez" (1576, mujer española, México, Documentos entre particulares: cartas y otros). 
catorce / 5 del presente por la primera calle de la Condeza, / nos hayamos con un ynfeliz enfermo / tendido en el suelo, que su situación nos / condolió (1800, hombre, México, Ciudad del Carmen, Capitanía general de Yucatán, provincia de Campeche, Virreinato de la Nueva España, Documentos administrativos, CORDIAM).

Como puede observarse, pues, a la vista de los datos mostrados, hay ejemplos de quesuismo documentados en textos de autores cultos y en cartas o documentos administrativos, tanto en España como en América, en distintos momentos de nuestra historia lingüística ${ }^{6}$. En un principio, su presencia no es muy significativa, pero va ganando terreno hasta convertirse, en los últimos tiempos, en una construcción muy frecuentada.

Es de notar, no obstante, que dicho fenómeno, pese a figurar en nuestra lengua desde la época medieval, no haya merecido un estudio esmerado hasta el momento y que sean pocas las gramáticas que le han prestado atención, quizás por quedar alejado del canon lingüístico, tal y como señalan Amorós Negre y Verde Ruiz (2012, p. 49):

No obstante, por lo general, los tratados gramaticales, centrados mayoritariamente en la descripción de los patrones propios de la variedad estándar escrita..., han prestado muy poca atención a las funciones comunicativas de las formas lingüísticas y se han circunscrito en gran manera al nivel oracional... Este hecho ha revertido muchas veces en la omisión o imprecisión en la explicación y en el tratamiento a construcciones controvertidas o tildadas de incorrectas por la gramática normativa, que muestran, sin embargo, gran vitalidad en el discurso oral: Es un chico que siempre están hablando de él, La niña que sus padres viven en Benavente; Allí fue que la conocí, etc. Se trata de estructuras lingüísticas en las que intervienen relativos sobre las cuales el lingüista debería también dar cuenta, estudiar su frecuencia, sus valores y sus ámbitos de aceptabilidad comunicativa, a pesar de que rebasan las fronteras del tradicional canon lingüístico.

${ }^{6}$ Los datos que maneja DeMello (1992) le permiten afirmar que los reemplazos de cuyo son más frecuentes en las ciudades americanas que en las españolas (28\% en América, frente a un $8 \%$ en España). No obstante, el número de ejemplos de quesuismo que localizó es mínimo (sólo 8) y no permite extraer conclusiones fiables. En cuanto al corpus manejado para este trabajo, mucho más amplio, no es posible sostener tal afirmación, aunque sí parece que en el CORPES el número de ejemplos americanos es mayor al de ejemplos peninsulares, como luego veremos. 
Es evidente que se trata de una construcción que requiere de análisis más profundos; pero, pese a la afirmación de estas autoras, parece que en los últimos años está empezando a despertar interés entre los estudiosos de la sintaxis del español (DeMello 1992; Tsutsumi Hernández 2002; Nishimura 2003; Moschin y Read 2010; Carrasco Aguilar, Ferado García y Solís Carrillo 2012; Sánchez Lancis 20147). Asimismo, al tratar las oraciones relativas de pronombre pleonástico o reasuntivo, la RAE, junto con la ASALE (2010, pp. 852-853), presta atención a este fenómeno e incluye el quesuismo como una tendencia de la lengua oral o de registros informales de la lengua escrita y menciona que

el término es adecuado solo en parte, ya que las formas que y su no son contiguas en todos los casos (Tenía una novia que a su padre le encantaba ir al campo). A ello se añade que el posesivo se sustituye por el artículo, como en Tenía una novia que a la madre le encantaba ir al campo;

ejemplos ampliamente documentados en el español actual a los que luego me referiré. Como vemos, pues, aunque aún escasos, ya hay trabajos que comienzan a analizar este fenómeno no sólo como una construcción incorrecta, sino como una estructura usada comúnmente por los hablantes.

En esta línea, en el presente trabajo me concentraré en los casos de quesuismo documentados en el español actual -tanto en el americano como en el europeo-, para lo que recurriré a corpus como el CREA, el CORPES XXI, el COSER y el ESLORA, así como a datos que se pueden obtener directamente de Google, y a una encuesta realizada a 58 informantes, con el fin de obtener un panorama lo suficientemente amplio de la extensión de este fenómeno que parece suponer, como apunta Sánchez Lancis (2014), una gramaticalización del relativo, que se ve desprovisto de sus funciones sintácticas, asimiladas al sintagma introducido por el posesivo, y se convierte en una mera marca de subordinación ${ }^{8}$.

7 También Picallo y Rigau (1999) hacen referencia a la sustitución de cuyo por que su, aunque no utilicen el término quesuismo en su exposición.

8 Aunque sin utilizar esta terminología, ya DeMello (1992) anticipaba que, mientras el otro elemento marca la posesión, que funciona en esta estructura como un mero conector, nexo o enlace. Habla también de lexi- 
A continuación, analizaré los tipos de texto en los que aparece, así como las características de los hablantes que recurren a esta construcción y las situaciones comunicativas en que la emplean. También me detendré en las construcciones en que se documenta y en la naturaleza de los sustantivos con los que suele aparecer e intentaré dar cuenta de los posibles factores que influyen en su uso ${ }^{9}$.

\section{EL QUESUISMO EN LOS CORPUS DEL ESPAÑOL ACTUAL}

Como dije anteriormente, he realizado la búsqueda de casos en diversos corpus que recogen ejemplos del español actual. En el Corpus Oral y Sonoro del Español Rural (COSER) sólo he localizado dos, lo que puede llevarnos a pensar que es una construcción más extendida en las áreas urbanas:

8. I1: Y esta, la madrina, la madre de el novio. Y este el padre. [HS: I2 El padre.] Ay, el padre que su hija lo quería y se nos ha muerto (2007, mujer, 85 años, Bandaliés, Loporzano, Huesca, COSER).

9. I1: Los hombres en Madrid, como ellos están trabajando y ellas también, pues tienen que hacer los dos las tareas pa irse a trabajar. Pero..., si está la mujer en su casa, yo tengo una hija en Madrid, que su marido está en el banco y, y ella no va a trabajar y el marido no hace nada (1991, mujer, Los Navalmorales, Toledo, COSER).

calización, pero, obviamente, en distintos términos a los que se utilizan en la lingüística actual.

${ }^{9}$ He restringido el campo de estudio de este trabajo al análisis del quesuismo y, por ello, pese a ser consciente del interés que conllevan, no me he centrado en construcciones de relativo más artículo con valor posesivo ("la niña que el padre no la dejaba salir"), aunque respondan a la misma realidad lingüística, ni en otras construcciones citadas por DeMello (1992, p. 54), tales como "Tengo tres hermanos de los cuales soy encargada de su tutela" o "Conozco muchas variedades de flores que no puedo detallar los nombres". Todas ellas son expresiones alternativas al uso de cuyo. Además, en los datos que maneja, son más frecuentes que el quesuismo, pues de 25 casos de reemplazo de cuyo, sólo 8 son de que su. En las encuestas realizadas a 58 informantes peninsulares, sin embargo, no parece que el reemplazo por relativo más artículo sea especialmente productivo. 
En el corpus ESLORA se documenta también un par de ejemplos, y es significativo destacar que en ambos casos tenemos que hablar de informantes con un alto nivel cultural:

10. y lo tiene aquí metido $<$ pausa/ $>$ el otro que su familia era de Noia y toda la vida hizo Santiago Noia <pausa_larga/> (SCOM_H13_014_hab1) (Hombre, universitario, 28, ESLORA).

11. $<$ pausa $/>$ no $<$ pausa $/>$ exactamente $<$ pausa $/>$ era $<$ pausa $/>$ un promedio tal $<$ pausa/ $>$ pero me acuerdo $<$ pausa $/>$ que esta < pausa/> compañera mía que su $m$ su en su casa $<$ pausa/> habia comercio de confección $<$ pausa/ $>$ de confección no porque no había confección $<$ pausa/ $>$ de telas $<$ pausa/ $>$ no había (SCOM_M33_005_hab1) (Mujer, universitaria, 67, ESLORA).

Por lo demás, la búsqueda de la secuencia que su en CREA nos depara un total de 33782 casos en 15291 documentos. Acotada la búsqueda a textos orales, encontramos 550 casos en 322 documentos, de los cuales 15 son ejemplos de quesuismo ${ }^{10}$. Sin embargo, he ampliado también la búsqueda en textos escritos de secuencias en las cuales que su acompaña a nombres de parentesco, puesto que en estas estructuras es más fácil encontrar la construcción de marras, como ya apuntaba Sánchez Lancis (2014): que su tío, que su hermano, que su hija, que su mujer, que su primo, que su familia, que su esposa..., y en esos casos, los ejemplos de quesuismo son, efectivamente, más frecuentes. Quiero llamar la atención sobre el hecho de que los pocos ejemplos de quesuismo que he encontrado en textos escritos -téngase en cuenta que se trata de una búsqueda limitada a los nombres de parentesco- pertenecen al teatro, género que hace de la orali-

10 Además, hay casos de dudosa interpretación, como el siguiente: "Ahora, en principio, hay más libertad, yo lo veo con mis hermanas, pero que también la juventud ha cambiado. Porque yo me acuerdo que antes salíamos, vamos, en mi caso, quedábamos a las cinco o cinco y media, con la pandilla, o sea, o con mi novio o lo que sea, pero ahora yo lo veo con mis hermanas, que su hora de salir de casa es a partir de las nueve de la noche, entonces si la movida, claro" (Oral, conversación, Universidad de Alcalá de Henares, formalidad = baja, España). Éste puede interpretarse como sustituto de cuya hora de salir o como veo que su hora de salir. La sintaxis truncada, propia de la oralidad, dificulta la lectura. 
dad uno de sus rasgos inherentes. Propongo, a continuación, sólo unos cuantos casos:

12. Reaccionó como lo típico de cualquier marido que su mujer le dice que está enamorada de otro hombre. Reaccionó realmente muy mal (Oral, Hablando con Gemma, Telemadrid, 20.XI.96, España).

13. Es un registro público que se va a abastecer con información pública, cuya naturaleza de información, la materia del registro, será pública, y que su principal servicio será despachar consultas a quien vaya a pedirlo (Oral, Sesión pública ordinaria de la Honorable Cámara de Senadores México, formalidad $=$ alta, México $)^{11}$.

14. Y en plan nosotros que no estamos casados ni nada de eso. Y además rollo también en plan amor sin sexo digo, sexo sin amor, también se da mogollón de casos. No, o sea, yo en eso estoy totalmente en contra. O sea, a mí, una tía que su eso sea acostarse ¿Y por qué una tía? O un tío O un tío Una tía. $\mathrm{O}$ un tío, bueno, yo estoy hablando de mi caso o sea, de que yo soy una tía, ¿sabes? (Oral, formalidad = baja, España).

15. y tengo el ejemplo de de un muchacho que su mamá era mi niñera y era en realidad ella vino del campo directamente, ni siquiera sabía hablar español, o sea, podíamos decir una india directamente, ¿no? (Oral, mujer de 36 años, arquitecta, formalidad = baja, Bolivia).

16. ¿Tienes amigos entre ellos? ¿Entre los nicaragüenses? Casi todos. Sí, ¿te quieren? Claro. ¿Seguro? Seguro. Bueno pues, ahora vamos a oír a a Magdalena. A a esta madre que bueno, que a su marido lo mataron los contras y que tenía ocho hijos, para que hable un poco de ti, a ver (Oral, Búscate la vida, 15.IV.86, TVE 2, España) ${ }^{12}$.

17. Sacerdote joven (aparte): Ante estos crédulos me creo como aquel san José, que su mujer sin contacto carnal encinta se halló (1981, Homero Aridjis, Espectáculo del año dos mil, teatro, México).

11 Obsérvese cómo en este ejemplo conviven cuyo y que su.

12 Estamos también ante un caso de quesuismo, aunque haya una preposición intercalada entre el relativo y el posesivo. 
18. Pero luego se le ocurrió a Padilla, ése que su mujer veía a la Virgen, que ¡qué coño!, si hacían el amor libre que lo siguieran haciendo un rato con nosotros. Se lo decimos a las tías y saltan las cabronas que ellas hacían el amor libre con quien les daba la gana (1990, José Luis Alonso de Santos, Trampa para pájaros, teatro, España).

19. Uno tenía un hijo comunista, que estudiaba medicina en Madrid, y estaba todo el día acojonado por si le habían cogido en cualquier lado; y el otro, que me parece que era de Úbeda, tenía una mujer de esas que ven a la Virgen, y iba la gente a su casa a que le curara a los chicos, y se le llenaba el comedor de paralíticos, ciegos... le tenían al hombre amargada la vida. Fíjate qué partidas de dominó: uno con una hija puta, el otro con un hijo comunista, otro que su mujer ve a la Virgen, y yo con un hermano medio maricón. ¡Joder! ¡Lo que yo te diga! Le metíamos unas hostias a la mesa de mármol con las fichas, que la agujereábamos (1990, José Luis Alonso de Santos, Trampa para pájaros, teatro, España).

Si continuamos con el análisis de los corpus, observamos que en CORPES XXI -aunque, de nuevo, obviamente, no todos son de quesuismo- se documentan 6848 casos en 4683 documentos de que su ${ }^{13}$; de ellos, 4148 (en 2892 documentos) son americanos, por lo que parece, pues, que la secuencia que su es un tanto más frecuente en estos textos, pero, dado que no he podido revisar íntegramente los documentos, no estoy en condiciones de afirmar, como hace DeMello (1992), que el quesuismo sea un fenómeno más frecuente en América. Para la búsqueda de ejemplos, he procedido de manera algo diferente a como lo hice con los datos del CREA, puesto que los sistemas de búsqueda son un tanto distintos: primero, he buscado en textos orales y en textos de Internet y no he localizado ningún caso de quesuismo. Después, he seleccionado los textos de teatro y tampoco hallé ningún ejemplo. A continuación, he realizado una búsqueda aleatoria en la que analicé alrededor de mil ejemplos ${ }^{14}$. Propongo una muestra:

20. ahí está el chofer. Rápido, me dice secamente. Doy la vuelta y observo a los pasajeros, todos conocidos. La señora loca, el

13 En una búsqueda realizada en julio de 2018.

14 He analizado los 250 primeros ejemplos y los 250 últimos, y realizado algunas calas entre los años intermedios. 
muchacho ignorado por su novia, la adolescente embarazada, la mujer que su marido le quitó todo, el señor que su vida es un asco, el anciano viudo, el niño del disfraz de conejo, todos ellos están aquí. Me ven fijamente, me siguen con su mirada (2006, José Juan Aboytia, “Tiovivo de equinos dementes”, en Contiene escenas de ficción explicita, México, CORPES XXI).

21. A diferencia del Sátiro que su única motivación es aplacar -complacer su instinto sexual- el latinlover aspira, como el legendario Don Juan que nos describe Tirso de Molina, a dejar su huella en las mujeres, es decir, el deseo de volverlo a ver, la necesidad angustiosa de dejarse poseer nuevamente (2001, Jorge Luis Oviedo, "El latinlover", en El cazabrujas y otros personajes, Honduras, CORPES XXI).

22. palenquera y raizal que propone el Acuerdo se materializa en seis aspectos: 1) la selección de potenciales beneficiarios que se encuentren en último año de su educación media. Deben estudiar en colegios ubicados en municipios seleccionados por la Universidad, que cumplan dos criterios: económico -municipios más pobres del país- y demográficos -municipios que su población sea mayoritariamente negra, afrocolombiana, palenquera o raizal (2016, Margarita María Rodríguez Morales, Tensiones para la inclusión real en la educación superior..., Colombia, CORPES XXI).

23. consumir petróleo durante un cierto período de tiempo para debilitar a un grupo terrorista que se financia con la producción de combustibles fósiles, con lo que paga elevados sueldos a sus mercenarios, y que pretende cambiar su forma de vida por una interpretación estricta de una de las varias religiones que pueblan el mundo. Una iniciativa ciudadana que su acción lleve: 1) a bajar el precio del petróleo en los mercados por la falta de demanda; 2) a los gobiernos afectados por esta movilización a iniciar un bloqueo económico y a no escudarse en vanos discursos sobre el mercado libre y el capitalismo, que no fueron obstáculo para los bloqueos (2015, Carlos Gámez Pérez, "Imaginar Europa después de París", Nagari, Miami, nagarimagazine.com, 1.XII.15, EE. UU., CORPES XXI).

24. quien luego que la Cámara votara contra un proyecto del delegado obrero, le manifestó: "Si queríamos los trabajadores leyes de esa naturaleza que mandáramos a trabajadores como nosotros y no a tanto hacendado y abogados de corpo- 
raciones que su labor consistía en mantener privilegios para sus representantes" (2001, Arturo Bird Carmona, A lima y machete, Puerto Rico, CORPES XXI).

25. Ello significa que cada actividad llevará implícito básicamente un objetivo, pero no se descarta que pueda perseguir paralelamente otro objetivo de forma secundaria. Ya que si bien hay un tipo de actividades que su objetivo principal sería el utilitario, en cuanto a prevención y mantenimiento, y a la vez pueden o no llevar un objetivo recreativo de forma secundaria; lo mismo a la inversa, por ejemplo los bailes, o los juegos, básicamente son actividades (2001, Pilar Pons Geis, Tercera edad, actividad física y salud. Teoría y práctica, España, CORPES XXI).

Según puede observarse, en CORPES XXI es posible encontrar bastantes casos en los que la secuencia objeto de estudio no acompaña a nombres [+humanos] de parentesco; lo mismo ocurre en Google, donde hay un número importante de ejemplos, sobre todo en blogs y otros tipos de texto de carácter coloquial:

26. 9 millones de euros ésos son los beneficios de TdCO una empresa que su sede no está en Córdoba viva la república bananera (El Muerto, 05.IV.2018, 17:59, http://cordopolis. es/2018/04/05/una-veintena-de-coches-funebres-recorrecordoba-en-protesta-por-la-construccion-de-un-tanatorio, España).

27. La historia de la chica que su novio le pegaba por cada "like" que recibía en Facebook (http:/ / elblog.com/internacionales/registro-48452.html).

28. él es un jugador que su máxima cualidad es la de crear fútbol (https://gramaticojac46.wordpress.com/2018/03/24/elquesuismo/).

29. Å, el pequeño pueblo que su nombre consta sólo de una letra, está situado al extremo oeste de las islas Lofoten. Tras sus acantilados se abre la mejor panorámica del mar de Noruega y, en días claros, pueden divisarse las islas de Røstøyan y Værøy (http:/ / marina-paul.com/20-fotos-haran-quierasvisitar-las-islas-lofoten/). 
30. No es mi intención hacer una extensa biografía de este gran escritor, sino hacer un pequeño homenaje a un hombre que su obra cambió e influyó en mí y en quienes lo han leído (http://imaginacionalpoder77.blogspot.com/2018/01/unhomenaje-salvador-borrego.html).

31. Conoce al árbol que sus hojas tienen 4 veces más vitamina $\mathrm{A}$ que las zanahorias, 3 veces más potasio que los plátanos, 4 veces más calcio que la leche, 3 veces más hierro que las espinacas, 7 veces más vitamina $\mathrm{C}$ que las naranjas y 2 veces más proteínas que el yogur (https://www.invasionverde.com/ $\mathrm{blog}$ /plantas-unicas).

32. El ajolote es una maravilla de la naturaleza, es un animal que su investigación en gran escala podría salvar miles de vidas a lo largo del mundo (https://steemit.com/steemit/@ julioc94/10-animales-del-fondo-marino-que-quizas-aun-noconozcas).

A la vista de los datos encontrados, se puede concluir que estamos ante una estructura relativamente frecuente en español actual, que se documenta tanto en textos orales -en los que su frecuencia de uso es mayor- como escritos, al tiempo que figura sobre todo en textos de carácter coloquial, lo cual no obsta para que lo encontremos también en documentos de carácter formal (ejemplos 22 y 25) y no sea ajeno, como ha podido observarse, a textos de carácter político, jurídico, o de temas de salud, o a textos literarios teatrales. Los hablantes que emplean que su no han de ser tachados como "vulgares", ni mucho menos, dado que localizamos ejemplos como (10) u (11) en que los informantes tienen una formación sobresaliente, casos en que tiene más que ver el tipo de situación comunicativa que la formación académica.

En cuanto al tipo de hablantes que lo utiliza ${ }^{15}$, hay tanto hombres como mujeres, pero es difícil establecer un patrón en

15 Para conocer la realidad sociolingüística de los hablantes que recurren a esta estructura, he realizado una encuesta cuyos resultados se analizarán a continuación. Moschin y READ (2010, p. 90), por su parte, han trabajado con dos grupos de estudiantes de secundaria, de entre 16 y 17 años y 20 y 25 , de diferente posición socioeconómica, y realizan un test sobre el uso de cuyo. Las autoras observan que, de los 205 ejemplos manejados, sólo hay 8 casos en los que se usa bien el relativo; en los demás, hay paráfrasis, creación de oraciones coordinadas o yuxtapuestas y, sobre todo, 
cuanto al nivel de instrucción recibido, ya que, como hemos visto, los hablantes cultos recurren a esta estructura en conversaciones relajadas. También podemos encontrarla en textos formales escritos por autores cultos -aunque, eso sí, en aquellos en los que la preocupación estilística no es lo primordial-y en blogs y páginas de Internet escritas por todo tipo de hablantes. A la luz de esta observación, resulta provechoso acudir a los resultados obtenidos por DeMello (1992), quien en su momento analizó el quesuismo dentro del proyecto "Estudio coordinado de la norma lingüística culta de las principales ciudades de Iberoamérica y de la Península Ibérica". Sus informantes eran únicamente hablantes cultos, lo que le lleva a rebatir la hipótesis de que el quesuismo forma parte del habla vulgar. Recojo algunas de sus palabras en este sentido:

En el presente estudio los informantes que utilizan esta construcción son todos individuos muy cultos, e incluyen arquitectos, ingenieros, abogados y catedráticos. En efecto, cuatro de los ejemplos de los reemplazos por "cuyo" se encuentran en conferencias dadas por profesores universitarios (1992, p. 67).

De todas formas, como el propio autor señala, no podemos olvidarnos de que cuyo, al menos en el caso de los informantes cultos con los que trabaja, sigue siendo más frecuente que sus reemplazos $(75 \%$ frente a $25 \%)$, como también he podido observar en la encuesta a la que me referiré en el siguiente apartado.

Por último, en lo que a parámetros sociolingüísticos se refie$\mathrm{re}^{16}$, hay que llamar la atención sobre el hecho de que la presencia del quesuismo sea tan poco frecuente en el COSER, corpus que recoge la lengua oral del español peninsular rural contemporáneo. Los hablantes recurren a otras construcciones y, de hecho, tampoco usan cuyo (sólo hay 3 ejemplos de cuyo y uno de cuya).

A continuación, y antes de analizar con mayor profundidad los casos de quesuismo documentados, me detendré en el análisis de los datos obtenidos en la encuesta realizada a 58 informantes.

quesuismo; por ejemplo: "María compró un canario que sus patitas parecen escarbadientes".

${ }^{16}$ Sobre el parámetro etario insistiré en el apartado siguiente. 
ANÁlisis de los DATOS DE UNA ENCUESTA SOBRE EL QUESUISMO: UNA VISIÓN SOCIOLINGÜÍSTICA

Para completar la información sobre el uso del quesuismo en español actual, he realizado una breve encuesta a 58 informantes con el fin de observar, a partir de determinados parámetros sociolingüísticos, la extensión de este fenómeno y de su aceptación. Para su elaboración, he tenido en cuenta los siguientes parámetros: sexo, edad (de 15 a 25 años, de 26 a 40; de 41 a 60 o mayor de 60), origen (lugar de nacimiento), lugar de residencia y nivel de estudios (primarios; ESO o grado medio de FP; bachillerato o grado superior de FP; universitarios). El objetivo ha sido averiguar si alguno de ellos es decisorio a la hora de usar una u otra estructura. Es evidente que esta encuesta sólo puede entenderse como un test piloto, pues los datos son muy reducidos y no es posible obtener de ella resultados estadísticamente fiables. Sin embargo, al menos permite realizar una primera aproximación al uso del quesuismo y a la percepción que determinados grupos de hablantes tienen de esta construcción.

En total, he entrevistado a 30 mujeres y a 28 hombres. Por lo que respecta al nivel de estudios, he diferenciado entre estudios primarios (5 informantes); secundarios o formación profesional de grado medio (14 informantes); bachillerato o formación profesional de grado superior (14 informantes) y estudios universitarios (25 informantes). En cuanto a la edad, me he centrado, sobre todo, en una franja intermedia (13 informantes entre 26 y 40 años y 27 entre 41 y 60 ; la mayoría de ellos, en torno a los 45-55 años), aunque he recogido también una muestra de 8 hablantes menores de 25 años y de 10 mayores de $60^{17}$.

17 Como he comentado, estudiosos como Moschin y Read (2010) han trabajado ya con jóvenes. En mi caso, convivo día a día con estudiantes universitarios -jóvenes cultos entre los 18 y los 25 años- que afirman no usar nunca cuyo en la lengua oral. En los exámenes y ámbitos más formales, según he podido observar, aunque no usen que su, forma estigmatizada, recurren a paráfrasis que les permiten evitar el uso de cuyo. Dado, pues, que su discurso cotidiano ha sido ya analizado, he preferido centrarme más en otros segmentos de población. En cuanto al habla de informantes adultos, sólo he localizado un breve estudio: Alabí, Malacarne y Palacios (2012), quienes luego de examinar a hablantes de entre 40 y 60 años, concluyen lo siguiente: "El avance del empleo del «quesuismo» se ha registrado, como demuestran los datos expuestos en las matrices, en el habla de adultos cuya profesión no se halla vinculada con la actividad lingüística. En contraposición, el empleo de «cuyo» resulta frecuente en profesionales relaciona- 
En lo que se refiere al lugar de nacimiento o de residencia, he entrevistado a 16 andaluces residentes en Sanlúcar de Barrameda (Cádiz), a 4 informantes navarros que viven en Pamplona y a 38 personas de distinta procedencia, pero que residen en el área de Madrid y sus alrededores desde hace bastante tiempo.

A todos los informantes se les ha solicitado que realicen dos ejercicios. El primero pretende dar cuenta de las expresiones que, en su día a día, y en distintos contextos comunicativos, emplean o dicen emplear los diversos grupos de hablantes. Llegados a este punto, es importante hacer una aclaración: entre lo que un hablante piensa que utiliza y lo que realmente usa, en ocasiones, media una importante distancia, por lo que con este primer ejercicio es posible que nos encontremos más cerca del nivel de la evaluación que del uso real:

1. “¿Utilizas las siguientes construcciones?”:

a. He oído que su padre es el mayor de todos ${ }^{18}$.

Sí NO

$b$. Esa mujer que su marido vivía en Londres es la que ha comprado mi coche.

Sí NO

c. La empresa que a sus empleados les dé mejores condiciones ganará el concurso.

Sí NO

d. La empresa cuyos empleados sean más productivos tendrá más beneficios.

SÍ NO

$e$. La empresa que a su jefe le dieron el premio obtuvo importantes beneficios.

Sí NO

$f$. La empresa a cuyo jefe le dieron el premio obtuvo importantes beneficios.

SÍ NO

g. El chico que el padre es médico es el que me dio el libro.

dos con la actividad lingüística. Por ende, parece tener bastante asidero la implicancia de las características sociales, especialmente la profesión, en la elección de las realizaciones lingüísticas" (p. 15). De sus palabras, lo que nos interesa es que los adultos también utilizan esta construcción. Lo de la importancia de la profesión a la hora de recurrir al quesuismo parece bastante más cuestionable: sus resultados habrían sido fiables si se hubiera comparado a médicos y fontaneros, por ejemplo, pero no tiene mucho sentido comparar a lingüistas con otros profesionales, pues se supone que la nuestra, a diferencia de otras, es una profesión bastante más influida por la norma lingüística.

18 Se trata, simplemente, de una pregunta de control. La he eliminado del análisis, pero quiero resaltar el hecho de que hay hablantes, sobre todo los de menor instrucción, que dicen no emplearla. 
$h$. Me quedo con los recuerdos de cuyos chicos ${ }^{19}$. Sí NO

$i$. El chico que su padre es médico es el que me dio el libro.

j. El chico cuyo padre es médico es el que me dio el libro.

Como puede observarse, en el ejercicio he incorporado usos en que cuyo encabeza un sintagma con función de sujeto $(d y$ j) o un sintagma preposicional con función de complemento indirecto $(f)$. Con las mismas funciones, he incluido ejemplos de que su (sujeto: $b, i$; complemento: $e$ ). Asimismo, he incluido una oración canónica con que a sus $(c)$ : se trata de una construcción un tanto costosa por el orden de palabras, pero me ha permitido ver si los hablantes la rechazaban por la presencia de esta secuencia. También he mostrado un ejemplo como ejercicio de control (a); otro con un uso erróneo de cuyo $(h)$; y, por último, un ejemplo con artículo $(g)$ que me permitirá observar, como hacía DeMello (1992), si los informantes usan también otros reemplazos para cuyo, aparte del quesuismo.

Después, se propuso un segundo ejercicio para observar si los hablantes percibían el quesuismo como algo erróneo al verlo escrito en un texto. Se trata del siguiente fragmento, en que debían corregir los errores que localizaran:

María estaba muy ilusionada con la nueva oferta de travajo, pero a sus amigos no les convencía, porque la empresa no les parecía muy fiable; así que la dijeron que no convenía que aceptase ese puesto, ya que toda empresa que su único objetivo sea ganar dinero a costa de lo que sea, al final, no merece la pena.

Obsérvese que en este texto aparece una falta de ortografía (travajo), junto a un laísmo (la dijeron) y un quesuismo (toda empresa que su único objetivo). Los dos primeros actúan como distractores, pues lo que realmente me interesaba de este ejercicio era ver si los hablantes percibían que su en este contexto como algo no canónico o si les parecía aceptable.

Ahora, lo propio es mostrar los resultados obtenidos en ambos ejercicios. Comenzaré, por supuesto, con los referidos al primer ejercicio; para ello se incluyen tres tablas en función

${ }^{19}$ Se trata de un uso incorrecto de cuyo que se ha propuesto para saber si los hablantes tienen dudas sobre cómo integrar la palabra en una construcción, en caso de utilizarla. 
de los parámetros sociolingüísticos manejados (sexo, edad y nivel de instrucción). He optado por no elaborar una cuarta tabla con las diferencias dialectales para que los resultados no queden excesivamente atomizados, pues, aunque la mayoría de los hablantes vive en las provincias de Madrid y Cádiz, hay informantes procedentes de Sevilla, Huelva, Granada, Pamplona, Alicante, Guadalajara, Segovia, Zamora, Palencia, Cuenca, Galicia... e, incluso, Chile. En cuanto al lugar de residencia, no he encontrado un patrón de conducta diferenciador -como sí se verá en el análisis del segundo ejercicio respecto al laísmo-, ya que no parece que se planteen diferencias en el uso del quesuismo dependientes de este factor, sino que son otros los que parecen tener más relevancia a la hora de elegir la estructura canónica con cuyo o la construcción quesuista.

Antes de presentar las tablas y proceder a su análisis, me gustaría destacar cuáles son las construcciones más utilizadas. Los datos permiten concluir que "La empresa cuyos empleados sean más productivos tendrá más beneficios" es la más usada por nuestros informantes: en total, reconocen recurrir a ella 48 personas, lo que supone un $82.76 \%$ de los entrevistados. Le siguen "La empresa a cuyo jefe le dieron el premio obtuvo importantes beneficios" con 38 (65.52\%) y "El chico cuyo padre es médico es el que me dio el libro" con 30 (51.72\%). Así pues, se advierte que las construcciones con cuyo son las que mayor número de informantes dice utilizar -se entiende que no en todos los contextos, pues hay diferencias evidentes en los usos orales y escritos.

Les siguen en frecuencia de uso "El chico que su padre es médico es el que me dio el libro" (utilizada por 25 informantes, lo que equivale a un $43.1 \%$ ); "La empresa que a sus empleados les dé mejores condiciones ganará el concurso" ( $24=41.38 \%)$; "La empresa que a su jefe le dieron el premio obtuvo importantes beneficios" ( $16=27.59 \%)$; "Esa mujer que su marido vivía en Londres es la que ha comprado mi coche" $(15=25.86 \%)$; "El chico que el padre es médico es el que me dio el libro" (14 $=24.14 \%)^{20}$; por último, "Me quedo con los recuerdos de cuyos chicos", que sólo usan 3 informantes $(5.17 \%)^{21}$.

${ }^{20}$ El reemplazo por que el, que en las investigaciones de DeMello (1992) era mayoritario, aquí ocupa menos espacio que las construcciones canónica y quesuista.

${ }^{21}$ Esta última construcción resulta excesivamente chocante, y sólo parece resultarle natural a un informante madrileño menor de 40 años con 
Estos porcentajes varían, obviamente, según el parámetro sociolingüístico considerado. Así, a continuación, muestro una primera tabla con los datos absolutos y el tanto por ciento de las mujeres y hombres que utilizan o dicen utilizar cada una de las expresiones propuestas:

\section{TABLA 1}

Sexo

\begin{tabular}{|c|c|c|c|}
\hline Construcción & Mujer & Hombre & Total \\
\hline $\begin{array}{l}\text { b) Esa mujer que su marido vivía } \\
\text { en Londres es la que ha com- } \\
\text { prado mi coche. }\end{array}$ & $8(26.66 \%)$ & $7(25 \%)$ & $15(25.86 \%)$ \\
\hline $\begin{array}{l}\text { c) La empresa que a sus emplea- } \\
\text { dos les dé mejores condiciones } \\
\text { ganará el concurso. }\end{array}$ & $10(33.33 \%)$ & $14(50 \%)$ & $24(41.38 \%)$ \\
\hline $\begin{array}{l}\text { d) La empresa cuyos empleados } \\
\text { sean más productivos tendrá } \\
\text { más beneficios. }\end{array}$ & $22(73.33 \%)$ & $26(92.86 \%)$ & $48(82.76 \%)$ \\
\hline $\begin{array}{l}\text { e) La empresa que a su jefe le } \\
\text { dieron el premio obtuvo im- } \\
\text { portantes beneficios. }\end{array}$ & $4(13.33 \%)$ & $12(42.86 \%)$ & $16(27.59 \%)$ \\
\hline $\begin{array}{l}\text { f) La empresa a cuyo jefe le die- } \\
\text { ron el premio obtuvo impor- } \\
\text { tantes beneficios. }\end{array}$ & $18(60 \%)$ & $20(71.43 \%)$ & $38(65.52 \%)$ \\
\hline $\begin{array}{l}\text { g) El chico que el padre es médi- } \\
\text { co es el que me dio el libro. }\end{array}$ & $6(20 \%)$ & $8(28.57 \%)$ & $14(24.14 \%)$ \\
\hline $\begin{array}{l}\text { h) Me quedo con los recuerdos de } \\
\text { cuyos chicos. }\end{array}$ & $1(3.33 \%)$ & $2(7.14 \%)$ & $3(5.17 \%)$ \\
\hline $\begin{array}{l}\text { i) El chico que su padre es médi- } \\
\text { co es el que me dio el libro. }\end{array}$ & $13(43.33 \%)$ & $12(42.86 \%)$ & $15(43.1 \%)$ \\
\hline $\begin{array}{l}\text { j) El chico cuyo padre es médico } \\
\text { es el que me dio el libro. }\end{array}$ & $16(53.33 \%)$ & $14(50 \%)$ & $30(51.72 \%)$ \\
\hline
\end{tabular}

Puede observarse que en algunos casos los porcentajes son muy semejantes, pero llama la atención cómo en $(c)$ y $(d)$ o, incluso en $(f)$, aunque en este caso en menor medida, el porcentaje de hombres que recurre a las construcciones canónicas es muy superior al de las mujeres, pese a que éstas suelen ser más respetuosas con la norma. En sentido contrario, una oración quesuista como $(e)$ es usada por las mujeres en una míni-

estudios primarios, a un informante de Zamora, residente en Madrid, entre 41 y 60 años, y a una mujer de 81 años, con estudios de bachillerato. 
ma proporción en comparación con los hombres. Respecto a (b) y a ( $i$ ), construcciones quesuistas muy similares, es llamativo que se use más la segunda que la primera, tendencia que quizás se deba a la mayor longitud de la relativa en el primer caso, la cual podría haber retraído a algunos hablantes de usarla. De cualquier forma, es conveniente tener en cuenta que, tanto en el caso de las mujeres como en el de los hombres, predominan los usos de cuyo sobre los quesuistas; pero ambas construcciones son reconocidas y empleadas por los hablantes.

Si consideramos ahora el parámetro de edad, también hay algunas diferencias dignas de mención:

\section{TABLA 2}

\section{Edad}

\begin{tabular}{lcccc}
\hline & $\begin{array}{c}\text { De } 15 \text { a } 25 \\
\text { años }\end{array}$ & De 26 a 40 & De 41 a 60 & $\begin{array}{c}\text { Mayor } \\
\text { de } 60\end{array}$ \\
Construcción & & & & \\
\hline b) Esa mujer que su mari- $1(12.5 \%)$ & $4(30.77 \%)$ & $7(25.92 \%)$ & $3(30 \%)$ \\
do vivía en Londres es & & & \\
la que ha comprado mi \\
coche.
\end{tabular}


TABLA 2 (concluye)

\begin{tabular}{lcccc}
\hline & $\begin{array}{c}\text { De } 15 \text { a } 25 \\
\text { Consos }\end{array}$ & De 26a 40 & De 41 a 60 & $\begin{array}{c}\text { Mayor } \\
\text { de } 60\end{array}$ \\
\hline $\begin{array}{l}\text { j) El chico cuyo padre es } \\
\text { médico es el que me dio } \\
\text { el libro. }\end{array}$ & $3(37.5 \%)$ & $6(46.15 \%)$ & $14(51.85 \%)$ & $7(70 \%)$ \\
\hline
\end{tabular}

A la vista de los datos, es posible afirmar que en todos los grupos etarios predominan las construcciones con cuyo, aunque el porcentaje de uso parece ser mucho mayor a partir de los 40 años, sobre todo en el grupo de mayores de 60. Los casos de quesuismo, excepto en el grupo de los más jóvenes -pero recuérdese que el número de informantes es poco ilustrativo-, son muy similares independientemente de la edad. De nuevo, si comparamos $(b)$ e $(i)$, vemos que en todos los grupos hay predominio de $(i)$. Por último, el reemplazo por artículo $(g)$ se mantiene estable en todos los grupos, aunque siempre con menor presencia que el quesuismo.

Finalmente, estableceré la comparación según los distintos niveles de instrucción:

TABLA 3

Nivel de instrucción

\begin{tabular}{|c|c|c|c|c|}
\hline Construcción & $\begin{array}{l}\text { Prima- } \\
\text { rios }\end{array}$ & $\begin{array}{l}E S O \text { o } \\
\text { grado medio } \\
\text { de FP }\end{array}$ & $\begin{array}{l}\text { Bachillerato } \\
\text { o grado supe- } \\
\text { rior de FP }\end{array}$ & $\begin{array}{l}\text { Universi- } \\
\text { tarios }\end{array}$ \\
\hline $\begin{array}{l}\text { b) Esa mujer que su marido } \\
\text { vivía en Londres es la que } \\
\text { ha comprado mi coche. }\end{array}$ & $1(20 \%)$ & $3(21.43 \%)$ & $5(35.71 \%)$ & $6(24 \%)$ \\
\hline $\begin{array}{l}\text { c) La empresa que a sus } \\
\text { empleados les dé mejo- } \\
\text { res condiciones ganará } \\
\text { el concurso. }\end{array}$ & $3(60 \%)$ & $6(42.86 \%)$ & $6(42.86 \%)$ & $9(36 \%)$ \\
\hline $\begin{array}{l}\text { d) La empresa cuyos em- } \\
\text { pleados sean más pro- } \\
\text { ductivos tendrá más } \\
\text { beneficios. }\end{array}$ & $3(60 \%)$ & $9(64.28 \%)$ & $13(92.86 \%)$ & $23(92 \%)$ \\
\hline $\begin{array}{l}\text { e) La empresa que a su jefe } \\
\text { le dieron el premio ob- } \\
\text { tuvo importantes benefi- } \\
\text { cios. }\end{array}$ & $1(20 \%)$ & $5(35.71 \%)$ & $6(42.86 \%)$ & $4(16 \%)$ \\
\hline
\end{tabular}


TABLA 3 (concluye)

\begin{tabular}{|c|c|c|c|c|}
\hline Construcción & $\begin{array}{l}\text { Prima- } \\
\text { rios }\end{array}$ & $\begin{array}{c}\text { ESO o } \\
\text { grado medio } \\
\text { de FP }\end{array}$ & $\begin{array}{l}\text { Bachillerato } \\
\text { o grado supe- } \\
\text { rior de FP }\end{array}$ & $\begin{array}{l}\text { Universi- } \\
\text { tarios }\end{array}$ \\
\hline $\begin{array}{l}\text { f) La empresa a cuyo jefe le } \\
\text { dieron el premio obtuvo } \\
\text { importantes beneficios. }\end{array}$ & $2(40 \%)$ & $6(42.86 \%)$ & $11(78.57 \%)$ & $19(76 \%)$ \\
\hline $\begin{array}{l}\text { g) El chico que el padre es } \\
\text { médico es el que me dio } \\
\text { el libro. }\end{array}$ & $2(40 \%)$ & $2(14.28 \%)$ & $3(21.43 \%)$ & $7(28 \%)$ \\
\hline $\begin{array}{l}\text { h) Me quedo con los recuer- } \\
\text { dos de cuyos chicos. }\end{array}$ & $1(20 \%)$ & $1(7.14 \%)$ & $1(7.14 \%)$ & $0(0 \%)$ \\
\hline $\begin{array}{l}\text { i) El chico que su padre es } \\
\text { médico es el que me dio } \\
\text { el libro. }\end{array}$ & $1(20 \%)$ & $6(42.86 \%)$ & $9(64.28 \%)$ & $9(36 \%)$ \\
\hline $\begin{array}{l}\text { j) El chico cuyo padre es } \\
\text { médico es el que me dio } \\
\text { el libro. }\end{array}$ & $3(60 \%)$ & $4(28.57 \%)$ & $4(28.57 \%)$ & $19(76 \%)$ \\
\hline
\end{tabular}

En este caso, sí habría que señalar algunas diferencias que parecen significativas: el ejemplo $(d)$ es destacable por el uso canónico de cuyo superior al $90 \%$ cuando se trata de los informantes con bachillerato o universitarios, frente al $60 \%$ en el de los informantes con estudios elementales u obligatorios. La misma diferencia porcentual se observa a propósito de $(f)$, en que el uso de cuyo indica que los universitarios y bachilleres superan en un $30 \%$ a los hablantes de ESO o estudios primarios $^{22}$. En el caso de $(j)$, también los universitarios son quienes más recurren a cuyo con una diferencia notable respecto a los demás grupos, excepto el de los hablantes con estudios primarios -aunque debe recordarse que en este último grupo contamos con sólo 5 informantes. Por lo demás, una estructura quesuista como $(e)$ es mucho menos frecuente entre los universitarios. Llama, sin embargo, la atención que el mayor porcentaje de uso declarado de la estructura quesuista de $(i)$ surja de los informantes con estudios de bachillerato. En cuanto al reemplazo por relativo más artículo, no parece importante en ninguno de los grupos, a excepción del constituido por individuos con estudios primarios.

${ }^{22}$ Como era de esperar, ninguno de los universitarios encuestados reconoce usar $(h)$. 
Es evidente que todos los participantes dicen usar cuyo, aunque también incurran en el quesuismo. Sin embargo, la formación, en sus diversas categorías, parece tener mayor relevancia que los demás parámetros considerados en este estudio, puesto que, aun cuando todos los grupos utilicen que su en mayor o menor medida, los universitarios son quienes más reconocen usar cuyo, lo que explicaría algunos de los resultados, dispares por lo general, del segundo ejercicio. Prácticamente, todos corrigen la falta de ortografía ${ }^{23}$, pero muchos no consideran dignos de corrección ni el laísmo ${ }^{24}$, sobre todo los del área madrileña, ni el quesuismo.

De los 58 informantes encuestados, 16 corrigen el quesuismo reemplazándolo por cuyo; he aquí un dato que debemos destacar: todos ellos son universitarios, salvo dos mujeres con estudios de bachillerato ${ }^{25}$. Esto permite afirmar que el nivel de instrucción tiene relevancia, como ya hemos visto, en el caso de la lengua escrita. Así, aunque ha quedado demostrado que los hablantes universitarios declaran usar la construcción no canónica, tal y como reflejan los resultados del ejercicio anterior, es posible que lo hagan sólo oralmente o en textos en los que no

${ }^{23}$ Llama la atención el caso de una universitaria madrileña menor de 25 años que no lo hace. Por lo demás, hay un hombre madrileño menor de 40 con estudios primarios, una mujer andaluza de entre 41 y 60, también con estudios primarios, y una mujer madrileña de entre 26 y 40 años con estudios de ESO que no corrigen nada del texto. En estos últimos casos hay que contar con la dificultad de los informantes para reflexionar sobre el uso de la lengua.

${ }^{24}$ No es el caso de los informantes andaluces, pues, como era de esperar, prácticamente todos corrigen el laísmo.

${ }^{25}$ Los informantes universitarios que corrigen todo (ortografía, laísmo y quesuismo) son los siguientes: un hombre nacido en Granada mayor de 60; una participante de Madrid mayor de 60; otra de Vigo de más de 40 años residente en Madrid; una madrileña menor de 25; dos madrileñas entre 41 y 60; otra de Salamanca entre 41 y 60 residente en Madrid; una universitaria madrileña entre 26 y 40; un hombre de Cuenca entre 26 y 40 residente en Madrid; otro de Cáceres entre 41 y 60 residente en Madrid; otro de Alicante entre 41 y 60 residente en Madrid; y un universitario de Pamplona mayor de 60 años. Además, hay una mujer entre 41 y 60, y otra mayor de 60 con bachillerato o FP superior que corrigen también todas las construcciones no canónicas del fragmento. Asimismo, una informante madrileña con estudios universitarios (quien dejó pasar la falta de ortografía) corrige el laísmo y el quesuismo, y un informante universitario de Tenerife mayor de 60 corrige el quesuismo, pero no el laísmo. Hay también un universitario entre 41 y 60 años que conoce el fenómeno del quesuismo, pero decide no corregirlo por no considerar que esta construcción deba ser estigmatizada. 
haya una preocupación estilística. No obstante, cuando prestan atención a un texto -recuérdese que se les ha pedido que corrijan "errores"-, parece que, al verla escrita, tal construcción les resulta chocante. A los demás, sin embargo, no les llama la atención, aunque ha quedado demostrado que usan cuyo o conocen esa forma.

En cuanto a la forma por la que se sustituye la estructura quesuista, en su mayor parte, los informantes, como he dicho, emplean cuyo, pero hay unos pocos casos en que los hablantes sienten esta forma como extraña y recurren a otras estrategias. Así, una informante madrileña con estudios secundarios, al eliminar "que en toda empresa que su único objetivo" deja una oración fragmentada como la que sigue: "toda empresa, su único objetivo, es ganar dinero". Por su parte, una universitaria madrileña que vive en Toledo observa como incorrecto que su, pero no propone cuyo, sino que dice que habría que reescribir la oración. El caso es curioso, porque en el ejercicio 1 sólo dice usar las formas con cuyo. Por último, una mujer de Pamplona mayor de 60 años, con estudios secundarios, al ver extraña la misma estructura, ensaya otra opción: "toda empresa que como objetivo tenga ganar...", con la que construye una oración igualmente canónica.

Hay otro dato que quiero destacar: ningún andaluz (salvo un universitario granadino residente en Madrid desde hace 40 años) ha corregido el quesuismo, pero no me atrevería a hablar de una diferencia diatópica, pues parece que lo significativo aquí es el nivel de instrucción; además, aparte del informante que acabo de mencionar, sólo había una mujer andaluza universitaria entre mis informantes ${ }^{26}$.

Una vez analizados los datos, podemos concluir que cuyo sigue siendo una forma reconocida por todos los grupos de hablantes, lo que explicaría por qué, independientemente de que se use más o menos en determinados contextos, no ha desaparecido pese a que tenga que competir con construcciones como el quesuismo o el artículo más relativo, estructuras presentes, en mayor o menor medida, en todos los grupos sociolingüísticos. Realmente, como se observa en los datos de los corpus manejados, lo más significativo a la hora de recurrir a una u otra construcción va a ser el tipo de situación comunicativa y el género discursivo empleado.

${ }^{26}$ Hay que recordar que estas conclusiones han de tomarse con cautela debido a la muestra tan reducida con la que se ha trabajado. 


\section{Construcaiones CON QUeSUISMO}

Vistos los tipos de textos en los que más aparece el quesuismo y hechas algunas matizaciones sobre los hablantes que en mayor proporción señalan recurrir a él, me fijaré en los contextos en los que se observa y en algunas causas que pueden provocar tal aparición.

El quesuismo se encuentra frecuentemente con antecedentes y poseídos [+humanos], pero no podemos decir que esto sea un requisito, ya que hemos localizado casos en los que el relativo y el posesivo, aunque no sea lo más habitual, se refieren a entidades no animadas y no humanas, tales como principal servicio, vida, motivación, una empresa, nombre u hojas en una relación que no podríamos considerar exactamente como de posesión. Tsutsumi (2002), con los datos que maneja del español clásico, observa que, en el caso de poseídos no humanos, predominan las entidades abstractas en un $95 \%{ }^{27}$; en español actual, como se puede deducir de los datos presentados, aunque siguen predominando los términos abstractos, hay también entidades concretas: pueblo, árbol, sede, nombre..., lo que da cuenta de la extensión del quesuismo a otras construcciones.

Con los datos manejados, podemos concluir que esta estructura se ve, sobre todo, con nombres [+humanos] de parentesco (posesión inherente): la mujer que su marido, un muchacho que su mamá, la chica que su novio... ${ }^{28}$; con nombres [-humanos] que no se refieren expresamente a algo poseído, sino a casos en los que el antecedente es agente o experimentador: "A diferencia del Sátiro que su única motivación", "abogados de corporaciones que su labor...” y, como señala Tsutsumi (2002), con poseídos referidos a entidades abstractas: "Una iniciativa ciudadana que su acción lleve", "un jugador que su máxima cualidad...". Parece, pues, que estamos más cerca de una marca de geniti-

27 La estudiosa localiza también poseídos que implican cercanía respecto al poseedor: honra, apellido, lengua...

${ }^{28}$ En mi corpus sólo he localizado un caso en el que el poseído [+humano] no implica parentesco. Véase el ejemplo (22), en el que se refiere a población. Tsutsumi (2002), con los datos de los siglos XVI y XVII, llega a la misma conclusión respecto al predominio de los nombres de parentesco, aunque considera también casos en los que hay relaciones de afecto o desafecto (amigo, enemigo), relaciones a partir de un dominio social (vasallos) o de compraventa (esclavos). 
vo que de una marca de posesión propiamente dicha. En este sentido, para Tsutsumi (2002, p. 1034) que su se ve más en "una zona conceptual no prototípica de posesión”. De hecho, funciona igual que cuyo, el cual, como bien señalan Picallo y Rigau (1999, p. 1003), no sólo tiene la función semántica de poseedor (pertenencia) o tema, sino que también funciona como agente o autor ("Admiraba a Buñuel, cuyas películas había visto miles de veces”).

Además, la secuencia que su, una vez desfuncionalizado el relativo, que sólo marca la subordinación, aparece fundamentalmente en posición de sujeto de la oración adjetiva, aunque hay algún caso de atributo: (13) "y que su principal servicio será despachar consultas a quien vaya a pedirlo", u otros en los que funciona como complemento directo: (16) "A esta madre que bueno, que a su marido lo mataron los contras y que tenía ocho hijos", o el siguiente ejemplo de CREA con vacilación de determinantes:

33. Éstos normalmente eran compañeros más jóvenes, compañeros con otra experiencia de vida que su la lucha antifranquista la habian vivido en su infancia o en su adolescencia pero que al llegar aquí han descubierto un país que estaba abierto, un país que tenía que tenía futuro, en el cual ellos tenían un un lugar para hacer cosas, un lugar para desarrollarse (Oral, Búscate la vida, 15.IV.86, TVE 2, España).

También se localiza en ejemplos como (11): "pero me acuerdo $<$ pausa/> que esta $<$ pausa/> compañera mía que su $m$ su en su casa <pausa/> habia comercio de confección”, en que la secuencia relativoposesiva introduce un complemento de carácter circunstancial. Sin embargo, lo más habitual es, como he señalado, que cumpla la función de sujeto.

Asimismo, aunque estas construcciones posesivas aparecen fundamentalmente con verbos copulativos como ser o estar, no es posible hacer una generalización, ya que son muchos los casos con otros verbos: "una viuda, que su marido se dixo apellido de Balboa", "a estte que su ssobrino y haijado, don Francisco de Urttussáusttegui, lo rreziuió en su cassa y lo rremittió luego", "nos hayamos con un ynfeliz enfermo / tendido en el suelo, que su situación nos / condolio", "Ay, el padre que su hija lo quería", "cualquier marido que su mujer le dice", "que a su marido lo mataron los contras", "me creo como aquel san José, que su mujer 
sin contacto carnal encinta se hallô", "ése que su mujer veía a la Virgen", "otro que su mujer ve a la Virgen", "no a tanto hacendado y abogados de corporaciones que su labor consistía", "La historia de la chica que su novio le pegaba", "es un jugador que su máxima cualidad es la de crear fútbol", "Å, el pequeño pueblo que su nombre consta sólo de una letra", "hacer un pequeño homenaje a un hombre que su obra cambió e influyó en mí", "al árbol que sus hojas tienen 4 veces más vitamina A que las zanahorias", "es un animal que su investigación en gran escala podría salvar", "compañeros con otra experiencia de vida que su la lucha antifranquista la habian vivido".

Luego de analizar las construcciones en las que se utiliza, me centraré, a continuación, en las posibles causas de la aparición del quesuismo.

\section{FACTORES QUE MOTIVAN EL QUESUISMO}

Son varios los autores que han estudiado los potenciales factores que motivan la sustitución de cuyo por otras construcciones alternativas. Así, DeMello (1992) presta atención a la categoría del referente [+ / -humano] -punto sobre el que ya he insistido en el apartado anterior-; al hecho de estar ante oraciones restrictivas o no restrictivas; a las funciones sintácticas; y a los parámetros de sexo y edad; pero sus datos no le permiten confirmar que ninguno de estos cinco factores sea decisivo. Por ello, se hace necesario acudir a factores de distinta naturaleza y, en cuanto a las causas que favorecen el uso del quesuismo, es preciso aludir al carácter sintético de cuyo, extraño para el español, que hace que los hablantes, desde épocas muy tempranas, desgajen con frecuencia ambos valores -el relativo y el posesivo- en dos elementos más afines a la gramática de la lengua española y más transparentes para los hablantes. Recuérdense en esta línea las palabras de Brucart (1999, p. 408), recogidas por Amorós Negre y Verde Ruiz (2012, p. 50):

El fácil acceso de los hablantes al patrón reduplicativo, atestiguado en la mayoría de las lenguas y disponible como único esquema para las relativas en muchas de ellas, se manifiesta en la frecuente sustitución del adjetivo relativo posesivo cuyo(s)-cuya(s) por la fórmula analítica $<q u e+$ posesivo $>$. 
Sin embargo, las gramáticas ${ }^{29}$ y libros de estilo, así como los blogs dedicados a la norma lingüística, tan frecuentes en la actualidad, insisten continuamente en lo erróneo del quesuismo, lo que hace que los hablantes cultos intenten (intentemos) a menudo obviar esta construcción, aunque luego en contextos informales acaben (acabemos) recurriendo a ella. Recuérdese el ejemplo (13) ya citado: "Es un registro público que se va a abastecer con información pública, cuya naturaleza de información, la materia del registro, será pública, y que su principal servicio será despachar consultas a quien vaya a pedirlo". Se trata de un texto oral formal en la Cámara de Senadores de México, en que el hablante, luego de usar cuyo, inmediatamente recurre a la construcción con que su, más espontánea.

Carrasco Aguilar et al. (2012) aluden a la dificultad que supone el uso de cuyo para los hablantes, lo que explica vacilaciones como la que acabo de citar, ya que "tiene carácter de relativo y de genitivo a la vez, pero no sólo expresa la idea de poseer algo, sino que puede establecer relaciones de otros tipos entre las frases nominales con las que se relaciona" (p. 90), como es este caso, en el que, realmente, no se trata de una relación de posesión, sino de marca de agentividad.

Sánchez Lancis apunta otra de las posibles causas del quesuismo:

Por todo ello, independientemente de si la alternativa, más que sustitución, del adjetivo-relativo 'cuyo' por la combinación 'que su' representa un auténtico cambio sintáctico en español, una innovación con posibilidades de adopción y difusión, o sólo se queda en un uso erróneo fruto de una literal traducción sintáctica ('cuyo' [con los valores de relativo + posesivo sin materialización fónica] > 'que su' [relativo + posesivo con materialización fónica]), lo que sí está claro es que este tipo de estructuras son consecuencia de la tendencia propia de las lenguas románicas, y sobre todo del español, de sustituir los procedimientos sintéticos del latín, lengua casual, por las estructuras analíticas del romance, en donde el orden de palabras, junto al desarrollo del sistema preposicional, pasó a marcar definitivamente la nueva sintaxis (2014, p. 402).

Tsutsumi apunta razones pragmáticas que conllevan efectos estilísticos para explicar la presencia del quesuismo:

${ }^{29}$ La RAE y la ASALE (2010, p. 853) consideran esta construcción “impropia de los registros formales", por lo cual recomiendan evitarla. 
Por su parte que + su funcionalmente supone un desdoblamiento de la canónica forma cuyo. A diferencia de ésta, que + su es una forma más transparente, ya que tiene similitud fono-morfológica con los relativos que poseen el nexo que, y hace explícita la marca de posesión normal para tercera persona: su. A diferencia de cuyo, el desdoblamiento que + su hace explícitas las dos funciones que quiere indicar, pues presenta dos signos, tanto el nexo como la marca de posesión, de esta manera no se altera la relación isomórfica ideal de significante y significado. Lo anterior nos lleva a decir que cuyo es una forma poco privilegiada comunicativamente, en tanto que que + su posee eficiencia comunicativa (2002, p. 1032).

Su hipótesis es que se usa más que + su por su transparencia funcional. Además, afirma que si el hablante considera cercanas entre sí las entidades de la relación posesiva, usará más esta forma, mientras que, si considera que no hay una relación próxima, usará cuyo. Ésta es la razón por la que en los ejemplos mencionados se observa más el quesuismo en los casos de relaciones posesivas inherentes.

Moschin y Read reflexionan sobre la ausencia del uso de cuyo en estudiantes de secundaria, que tiene que ver con un intento de simplificación, unido a un mínimo dominio de la sintaxis:

A esto podríamos agregar que el hecho de que en la escritura sea ínfima su aparición, aun en los casos en los cuales sería necesaria, es un indicio probable del profundo desconocimiento con respecto a su empleo y, consecuentemente, de su significación. La alteración de la oración en aras de transformarla en estructuras simples, coordinadas o yuxtapuestas, dan cuenta no sólo de una búsqueda de simplificación en el uso del lenguaje sino también de un posible desconocimiento de la sintaxis que lleva a los alumnos en muchos casos, indefectiblemente, a la construcción de oraciones agramaticales (2010, p. 90).

Otras estudiosas como Caviglia y Malcuori también justifican la dificultad para usar cuyo por su singularidad dentro de los relativos, como ya he adelantado:

Este relativo tiene un comportamiento peculiar ya que ocupa el lugar del determinante de un nombre con el cual concuerda en género y número. Esto lo separa del resto de los pronombres relativos cuyas relaciones de concordancia, cuando las hay, se establecen con el antecedente. La complejidad y la singularidad 
de cuyo explican, como es sabido, su escaso uso en la lengua oral (2007, p. 45).

Y Alabí, Malacarne y Palacios (2012, p. 15), al analizar los datos de sesenta encuestados, concluyen que la mayoría de los que no emplean cuyo lo consideran una expresión muy formal y compleja, no lo tienen incorporado a su léxico o temen no ser comprendidos.

Observamos, pues, que son varias las causas que provocan que los hablantes recurran al quesuismo: la tendencia analítica del español como lengua romance, la facilidad de los hablantes para recurrir a estructuras reduplicativas, la transparencia formal que aporta eficiencia comunicativa, la complejidad y singularidad de cuyo o, simplemente, la identificación de éste como forma excesivamente culta.

\section{Conclusiones}

En este trabajo he llevado a cabo el análisis de las construcciones en que la secuencia que su aparece en lugar de cuyo. Tales construcciones están presentes en español a lo largo de toda la historia de la lengua: se ha observado que en la época clásica menudean en textos escritos por autores cultos; en español actual se documentan cada vez más en la oralidad y es posible encontrarlas también en textos escritos, sobre todo de carácter informal o en géneros como el teatro, que pretenden reflejar la oralidad.

El fenómeno analizado surge como alternativa al doble valor relativo y posesivo de cuyo y supone la gramaticalización de que, el cual se convierte en mera marca de subordinación. En muchos de los casos, realmente, el quesuismo podría funcionar como una variante invisible (Barra Jover 2009), puesto que el hablante usa alternativamente cuyo o esta construcción sin ser consciente de ello, y sin considerar estigmatizada, en principio, ninguna de las dos formas: su documentación en los corpus desde la época medieval como alternativa a cuyo, incluso en textos de autores cultos, da buena cuenta de ello.

Para comprender este fenómeno, he rastreado ejemplos de quesuismo en distintos corpus que me han permitido observar su extensión en el español actual. Para completar esta información, he realizado una encuesta a 58 hablantes para la cual 
contemplé diversos factores que permitieran analizar la variación sociolingüística. Pese al carácter limitado de la muestra, de todos estos parámetros ninguno de ellos parece ser especialmente relevante a la hora de recurrir al quesuismo, aunque sí se ha podido comprobar que los hablantes con una formación superior recurren con mucha mayor frecuencia a cuyo que el resto. Según he observado, los hablantes que en la actualidad reconocen usar que su tienen distintos grados de instrucción y su empleo parece deberse más al tipo de situación comunicativa que al lugar que ocupan en la jerarquía cultural, tal y como se desprende de los datos presentados.

Por lo demás, su aparición se observa, sobre todo, con nombres [+humanos] de parentesco (posesión inherente) y, en menor medida, con nombres [-humanos] que no se refieren realmente a algo poseído, sino a casos en los que el antecedente es agente o experimentador, o con poseídos referidos a entidades abstractas. Hablamos de construcciones en las que en realidad no se da una relación de posesión, por lo que, en este sentido, como se ha apuntado, estaríamos ante un sustituto del genitivo.

En cuanto a las causas de su aparición y consolidación, se han mencionado en este trabajo la complejidad y singularidad de cuyo por ese doble valor relativo y posesivo; la identificación de éste como una forma excesivamente culta, sobre todo por parte de los hablantes más jóvenes; los factores de carácter pragmático; la facilidad de los hablantes para recurrir a estructuras reduplicativas; y la tendencia analítica del español como lengua romance.

Por último, es posible considerar que nos encontramos ante un cambio lingüístico en curso, que hoy por hoy supone un caso de variación lingüística asociada a determinadas situaciones comunicativas y que difícilmente supondrá un cambio lingüístico como tal: no podemos predecir la sustitución definitiva de una expresión por otra, en cuanto que cuyo, forma sintética extraña en nuestra lengua, pese a haberse sustituido por diversas construcciones a lo largo de la historia, parece mantenerse con fuerza en el registro formal escrito y continúa siendo la forma predominante tanto en la encuesta realizada como en los corpus manejados. Con todo, aunque no haya evidencia para suponer su desaparición y sí para augurarle buena salud, sobre todo en la lengua escrita culta, El pequeño pueblo que su nombre consta sólo de una letra es una construcción que, a pesar de las gramáticas normativas, seguiremos oyendo y empleando. 


\section{REFERENCIAS}

\section{Fuentes primarias}

CORDIAM = Academia Mexicana de la Lengua, Corpus diacrónico y diatópico del español de América (Cordiam), www.cordiam.org [consultado en julio y agosto de 2018].

COSER = Inés Fernández-Ordóñez (dir.) 2005. Corpus Oral y Sonoro del Español Rural, http:/ / www.uam.es/coser [consultado en julio y agosto de 2018].

CREA = Real Academia Española: Banco de datos (CREA) [en línea]. Corpus de referencia del español actual, http:/ / www.rae.es [consultado en julio y agosto de 2018].

CORPES XXI = Real Academia Española: Banco de datos (CORPES XXI) [en línea]. Corpus del Español del Siglo XXI (CORPES), http://www.rae.es [consultado en julio y agosto de 2018].

ESLORA = Corpus para el estudio del español oral, http:/ / eslora.usc.es, versión 1.1 de marzo de 2018 [consultado en julio y agosto de 2018].

Serradilla Castaño, Ana 2018. Encuesta realizada entre noviembre y diciembre a 58 hablantes.

\section{Estudios}

Alabí, Graciela Mabel, Carla Malacarne y Gabriela Gladys Palacios 2012. "Avance del quesuismo sobre el pronombre relativo «cuyo» en el habla de adultos profesionales", en Actas de las I Jornadas de Jóvenes Lingüistas. Coords. Lucía Molina y María Elina Sánchez, Universidad de Buenos Aires, Buenos Aires, pp. 11-15.

Álvarez Martínez, M. Ángeles 1987-88. "Los pronombres el cual y cuyo, ¿dos relativos en desuso?”, Revista de Filología de la Universidad de La Laguna, 6/7, pp. 79-92.

Amorós Negre, Carla y Susana Verde Ruiz 2012. "Sobre los principios pragmático-discursivos en la descripción gramatical del español”, Pragmalingüística, 20, pp. 41-60, doi: 10.25267/Pragmalinguistica.2017.i25.

Barra Jover, Mario 2009. "Las variantes invisibles. Dos ejemplos del paso del español medieval al clásico", La transformación del castellano medieval: sistema, formas de transmisión y entorno social, Cahiers d'Études Hispaniques Médiévales, 32, pp. 17-32, doi: 10.3406/cehm.2009.2064.

Barra Jover, Mario 2011. "Variantes invisibles, emergencia y cambio lingüístico", en Asi se van las lenguas variando. Nuevas tendencias en la investigación del cambio lingüistico en español. Eds. Mónica Castillo Lluch y Lola Pons Rodríguez, Peter Lang, Bern, pp. 75-104, hal id: ffhalshs-00633001f.

Carrasco Aguilar, M., A.L. Ferado García y L.J. Solís Carrillo 2012. "Tengo un amigo que su papá es traductor o cuyo, una palabra en vías de extinción”, Mutatis Mutandis, 5, 1, pp. 86-99.

Caviglia, Serrana y Marisa Malcuori 2007. "Las oraciones de relativo en la interfaz gramática-discurso”, Estudios de Lingüistica Hispánica, pp. $31-54$. 
DeMello, George 1992. “Cuyo y reemplazos por cuyo en el español hablado contemporáneo”, Anuario de Lingüistica Hispánica, 8, pp. 53-71.

Elvira, JAvier 2007. "Observaciones sobre el uso y la diacronía de cuyo", en Ex admiratione et amicitia. Homenaje a Ramón Santiago, Ediciones del Orto, Madrid, t. 1, pp. 365-375.

Lorenzo, Emilio 1980. "El relativo cuyo", en El español de hoy: lengua en ebullición, $3^{\text {a }}$ ed., Gredos, Madrid.

Moschin, Ayelén y Valeria Read 2010. "Lengua en uso: consideraciones acerca del relativo cuyo", Pragmalingüistica, 17, pp. 80-91, doi: 10.25267/ Pragmalinguistica.2017.i25.

Nishimura, Kimiyo 2003. "Sobre el relativo posesivo cuyo y el llamado quesuismo en el español actual”, Lingüística Hispánica, 26, pp. 67-82.

Picallo, M. Carme y Gemma Rigau 1999. "El posesivo y las relaciones posesivas”, en Gramática descriptiva del español. Dirs. Ignacio Bosque y Violeta Demonte, Espasa Calpe, Madrid, t. 1, pp. 973-1021.

RAE y ASALE 2010. Nueva Gramática de la lengua española. Manual, Espasa, Madrid.

SÁnchez Lancis, Carlos 2014. "De la síntesis al análisis: diacronía del quesuismo en español", en Actes du XXVII Congrès International de Linguistique et de Philologie Romanes. Eds. Adam Ledgeway, Michela Cennamo et Guido Mensching, ATILF, Nancy, pp. 389-402, en http://www.atilf.fr/ cilpr2013/actes/section-4.html.

Tsutsumi Hernández, Ana Isabel 2002. "Relativos posesivos estigmatizados. El caso cuyo vs. que su", en Actas del V Congreso Internacional de Historia de la Lengua Española. Eds. María Teresa Echenique Elizondo y Juan Sánchez Méndez, Gredos, Madrid, t. 1, pp. 1029-1040. 
